\title{
DESBUROCRATIZAÇÃO E DESENVOLVIMENTO ECONÔMICO: SITUAÇÃO DOS MUNICÍPIOS PARA A IMPLANTAÇÃO DA REDESIMPLES EM SANTA CATARINA
}

Diego Wander Demetrio ${ }^{1}$

Ivoneti da Silva Ramos ${ }^{2}$

Andressa Sasaki Vasques Pacheco

\begin{abstract}
Resumo
A presente pesquisa analisa a situação dos municípios catarinenses para a implantação da Redesimples, apresentando o arcabouço legal que permite a simplificação e integração dos processos de abertura, alteração e baixa empresarial. A pesquisa é classificada como descritiva, do tipo estudo de caso, com pesquisa documental, observação e entrevista semiestrutura, com análises pelos métodos qualitativo e quantitativo em trinta e cinco municípios catarinenses. Com uma contextualização internacional e nacional por pesquisas que avaliam a facilidade de fazer negócios, seguido pelos marcos legais, a pesquisa explora uma análise detalhada para os municípios de Florianópolis e São José, passando a uma análise específica nos demais municípios, representando todas as regiões do estado. Como resultados, verifica-se a não observância legal quanto ao procedimento de Consulta Prévia, desconhecimento do próprio município de sua legislação e exigências, da visão arrecadatória e tempo demasiadamente longo para as análises destes elementos, importantes processos-chave para a dinamização da economia.
\end{abstract}

Palavras-chave: Desburocratização. Redesimples. Empresas. Desenvolvimento.

\section{DEBUROCRATIZATION AND ECONOMIC DEVELOPMENT: SITUATION OF THE MUNICIPALITIES FOR THE IMPLANTATION OF REDESIMPLES IN SANTA CATARINA}

\begin{abstract}
The present research analyzes the situation in Santa Catarina for the implantation of Redesimples, presenting the legal framework that allows the simplification and integration of starting, changing and closing business processes. The research is classified as descriptive, as a case's study type, with documentary research, observation and semi - standardized interview, using qualitative and quantitative methods in thirty - five municipalities of Santa Catarina. With an international and national contextualization for surveys that evaluate the ease of doing business and regulatory environment. The research explores a detailed analysis for the towns of Florianópolis and São José. As, for example, the checks are not valid for the prior consultation process, lack of knowledge of the municipality of its legislation and requirements, the collection perspective and too long time for the analysis of these elements, important key processes for the dynamization of the economy.
\end{abstract}

Keywords: De-Bureaucracy. Redesimples. Business. Development.

\footnotetext{
${ }^{1}$ Mestrando em Administração da Universidade Federal de Santa Catarina Especialista em Gestão Pública Municipal (2013) e Gestão Pública. Graduado em Administração (2011) pela Universidade Federal de Santa Catarina. Coordenador Estadual de Políticas Públicas do Sebrae/SC.

${ }^{2}$ Mestre em Economia (2006) e Graduada em Ciências Econômicas (2004) pela Universidade Federal de Santa Catarina. Professora Efetiva do Departamento de Administração Pública da ESAG na Universidade Estadual de Santa Catarina.
}

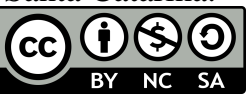

P2P \& INOVAÇÃO, Rio de Janeiro, v. 5 n. 1, p.195-218, Set./Fev. 2018. 


\section{INTRODUÇÃO}

Em períodos de crise econômica e financeira, ou ainda, em tempos de recursos mais escassos, a forma de administrar o bem público é colocada em discussão, principalmente no tocante ao modelo e à concepção de criação das políticas e ações públicas.

Kooiman (1993, p. 6 apud SECCHI, 2009, p. 359), relatando os movimentos impulsionadores da gestão pública, afirma que "a crescente complexidade, dinâmica e diversidade de nossas sociedades coloca os sistemas de governo sob novos desafios e que novas concepções de governança são necessárias”. Dentre os novos desafios encontra-se a necessidade da desburocratização como facilitador para o movimento da economia do país, uma vez que há o dispêndio de tempo e recursos de um empreendedor para a abertura formal do seu negócio, para só então começar a gerar renda e contribuir com os impostos e auxiliar no desenvolvimento econômico.

Historicamente é possível listar três tipos, ou modelos teóricos, de Administração Pública: Velha Gestão Pública (Convencional, ou Administração Patrimonialista), Nova Gestão Pública (Administração Pública Burocrática e Gerencial), e o modelo emergente, conhecido como Novo Serviço Público (DEMETRIO; GARRIDO, 2014).

No patrimonialismo, as ideias do clientelismo (troca de favores, prevalecimento de interesses privados em detrimento do interesse público) fizeram surgir um modelo sem, ou com pouca, referência de interesse público. No Brasil, isso pode ser observado principalmente na vinda de D. João VI, no início do século XIX, com a instalação do Governo Imperial, no qual, mesmo existindo constituição, sistema jurídico, serviço público e um governo, o País carecia de independência política (GOMES; OLIVEIRA, 2010).

Na Europa, o modelo teve início na Idade Média, predominando nas monarquias absolutistas dos séculos XV ao XVII, sendo substituído pelo modelo burocrático weberiano no século XIX (FROES; MELO NETO, 2006).

A Administração Burocrática surgiu de forma a combater a corrupção e o nepotismo, inerentes ao modelo anterior. Dessa forma, adotaram-se procedimentos legais rigorosos, estabelecendo requisitos previstos em normas, para viabilizar a prática de atos da Administração Pública (DEMETRIO; GARRIDO, 2014). O modelo propõe uma desconfiança prévia dos administradores públicos por parte da sociedade e, dessa forma, a autoridade é proveniente na razão e na lei (a autoridade racional-legal) para garantir a efetividade da contenção dos abusos (OLIVEIRA, 2010). 
O modelo burocrático é atribuído a Max Weber (1991), pois foi quem analisou e sintetizou suas principais características. De acordo com ele, seus principais eixos são a especialização, o controle e, principalmente, o racionalismo (WEBER, 1991). Portanto, a racionalidade técnica e econômica que Guerreiro Ramos (1989) irá designar de Homem Econômico, é predominante.

Nesta concepção, de controle e monitoramento das ações empresariais, o poder público disciplina e define exigências quanto ao processo de abertura, alteração e baixa de empresas de maneira a definir parâmetros e autorizar empreendimentos que estejam cadastrados, para que possam arrecadar e pagar seus impostos e que cumpram exigências de responsabilidade social, quanto à prevenção de riscos de perigo e incêndio, ocupação regular, segurança sanitária e ambiental, por exemplo. Sendo este o mote desta pesquisa, discute-se esse controle burocrático exercido na economia à luz de referenciais internacionais e do arcabouço legal para a desburocratização.

Na discussão iniciada, quanto aos modelos de administração pública, percebe-se o movimento de romper paradigmas burocráticos e trazer conceitos de eficiência, economicidade e integração como pertencente a outra definição teórica.

A Administração Pública Gerencial, ou Nova Administração Pública, em inglês New Public Management, apresenta-se como solução para os problemas da burocracia, priorizando a eficiência da administração, o aumento da qualidade dos serviços e a redução dos custos. Ressalta-se que a Administração Gerencial constitui um avanço quanto à participação mais intensa dos cidadãos, com ênfase na eficiência, na qualidade e efetiva concretização do regime democrático, mas não nega os preceitos básicos burocráticos (admissão de pessoal segundo critérios rígidos, meritocracia na carreira pública e sistema de remuneração estruturado). $\mathrm{O}$ avanço denota-se na função controle, que deixa de avaliar os processos em si e concentra-se nos resultados (BORGES, 2013).

No caso brasileiro, na busca por uma simplificação e facilidade de gerar negócios no país, como mecanismo de promoção do desenvolvimento econômico, respostas às demandas públicas e à eficiência, o Governo Federal propôs a implementação de sistemas informatizados que buscam a redução dos procedimentos de registro e legalização empresarial. Em 2007, houve a sanção da lei nacional da Redesimples, que estabelece diretrizes e procedimentos para a simplificação e integração de empresários e pessoas jurídicas. Contudo, apenas em 2016 o governo estadual catarinense encaminhou projeto de lei para discussão de parâmetros estaduais sobre o assunto. Portanto, buscando de fato a implementação integral da legislação questionase, qual a situação dos municípios para a implantação da Redesimples em Santa Catarina? 
No intuito de responder à pergunta, o trabalho apresenta na primeira seção uma breve introdução ao tema, na segunda seção destaca-se a discussão teórica a partir dos conceitos de desenvolvimento e crescimento econômico, seguidos pelo o marco legal envolvido nos processos de abertura, alteração e baixa empresarial. Na terceira seção apresentam-se os aspectos metodológicos, na quarta seção tem-se os resultados e por fim, na quinta seção são tecidas as considerações finais sobre o tema.

\section{REVISÃO TEÓRICA}

A escassez de conhecimentos, competências e de gestão, formam um obstáculo primordial ao desenvolvimento econômico (MOREIRA; CRESPO, 2012). Neste diapasão, surge uma importante inter-relação de melhoria no modelo operativo da gestão pública quanto a tornar mais dinâmico o processo de gerar negócios em uma economia; mais especificadamente aqui explorado pela abertura, alteração e baixa empresarial; e o desenvolvimento naquele território.

Quando explorado o conceito de Desenvolvimento Econômico, surge uma discussão teórica entre esse termo e seu relacionamento, subordinação ou causalidade com Crescimento Econômico. Para Bresser-Pereira (2008), economistas não-ortodoxos teriam essa discussão ideológica que, enquanto a primeira implica em melhor distribuição de renda, a segunda não necessariamente. Para o autor, "desenvolvimento econômico e crescimento econômico podem ter conotações diferentes, mas afinal são a mesma coisa quando são estudados de forma empírica ou histórica" (BRESSER-PEREIRA, 2008, p. 5). Neste artigo, toma-se como axioma essencial a interdependência e até cumulatividade entre os termos e, principalmente, que a desoneração de fluxo nos processos de legalização empresarial, trarão, necessariamente maior dinâmica e desenvolvimento para a nação.

Pessali e Dalto (2010, p. 11) corroboram tal afirmação à medida que "o desenvolvimento econômico depende das instituições e as instituições, ao mesmo tempo, são uma medida do desenvolvimento econômico. Assim, correlação e causalidade se confundem num processo cumulativo e circular". Para os autores, as empresas formam mais que uma engrenagem essencial para o desenvolvimento econômico, tornando-se uma importante medida desse.

A Teoria do Desenvolvimento Econômico, obra clássica de Schumpeter, explora que os empreendedores são a força motriz do crescimento econômico, devido à dinâmica de inovações e pela concorrência no mercado. Audrestsch, explora ainda que o empreendedorismo serve 
como mecanismo para o transbordamento e comercialização do conhecimento (BARROS; PEREIRA, 2008).

Por fim, apresenta-se na figura a seguir um referencial analítico sobre empreendedorismo e desempenho econômico, na qual há a introdução de inovação e/ou geração de maior concorrência com a criação de um novo negócio, que por sua vez exigem novas estruturas, maior eficiência e dinamismo, resultando em maior PIB e nível de emprego.

Figura 1: Empreendedorismo e Desempenho Econômico

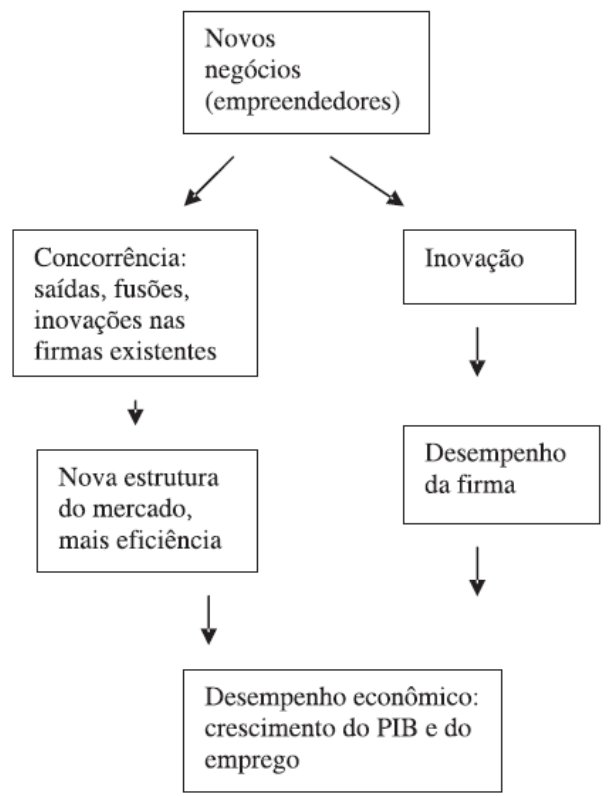

Fonte: BARROS; PEREIRA, 2008, p. 984.

Inúmeros estudos demonstram o relacionamento de desenvolvimento econômico e o empreendedorismo (BARROS; PEREIRA, 2008; STEL; CARREE; THURIK, 2005), inclusive com o processo de abertura empresarial (WORLD BANK, 2017).

O acesso ao empreendedorismo, principalmente pela criação de facilidades de abrir uma empresa nas diversas economias, demonstram uma associação entre essa variável e o coeficiente de GINI; que mede a desigualdade da distribuição de renda.

As pessoas de baixa renda são mais propensas a se beneficiar de uma regulamentação transparente, porque, ao contrário dos indivíduos ricos, eles não podem pagar peritos para ajudá-los a navegar no sistema e são mais propensas de exclusão das oportunidades econômicas quando a regulamentação empresarial é complicada (WORLD BANK, 2017, p. 19, tradução nossa).

A figura 2 apresenta essa relação: 
Figura 2: Economias onde é mais fácil abrir um negócio tendem a ter níveis mais baixos de desigualdade de renda em média

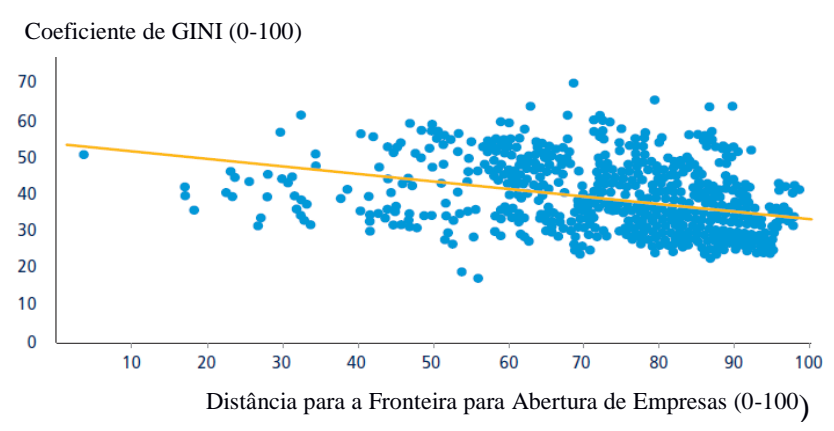

Fonte: WORLD BANK, 2017, p. 19, tradução nossa.

Portanto, após a localização no campo de estudo nos modelos teóricos da gestão pública e apresentação da relação desenvolvimento, crescimento, empreendedorismo e dificuldades para abrir uma empresa, passa-se a analisar pontualmente um referencial importante de análise e comparação dos processos de abertura, alteração e baixa empresarial: Doing Business.

\subsection{DOING BUSINESS}

O Grupo Banco Mundial, organização internacional de maior fonte de assistência para o desenvolvimento dos países, publica anualmente o relatório de análise das leis e regulamentações que facilitam e as que dificultam as atividades das empresas. Na sua décima quarta edição, o Doing Business 2017, analisa cento e noventa economias por meio de indicadores divididos em dez áreas; esses construídos e identificados a partir de base de pesquisa do Banco Mundial com mais de 130.000 empreendedores quanto aos principais obstáculos para a realização de negócios (WORLD BANK, 2017).

Tendo em vista que o escopo desta pesquisa se encontra em analisar a situação dos municípios nos processos de legalização empresarial, isto é, abertura, licenciamento, alteração e baixa, é oportuno conhecer em maior profundidade a dimensão que o Banco Mundial trata como abertura de empresas. A metodologia foi desenvolvida inicialmente por Djankov (et al., 2002) e é atualmente adotada com pequenas modificações realizadas pelo Banco Mundial. Esta área de análise faz parte do Doing Business desde a primeira edição, em 2004, quando integravam apenas 133 economias na análise.

Para a construção deste indicador são avaliados todos os procedimentos para a abertura e operação formal de uma empresa industrial ou comercial em cada uma das economias, inclusive com a avaliação do tempo, custo e capital social inicial mínimo requerido. Portanto, o indicador abertura de empresas possui quatro componentes, cada com $25 \%$ de peso; 
procedimentos, tempo, custo e capital mínimo. Para isto é verificado todos os procedimentos para a abertura de uma empresa limitada padrão da metodologia, sem o pagamento de quaisquer subornos ou outro ilícito, inicialmente pelas informações divulgadas oficialmente e posterior checagem com advogados societários, funcionários de cartórios e do governo, além de outros peritos locais. As informações são checadas até existir um consenso nas respostas (WORLD BANK, 2017).

Para fins de cômputo, é considerado um procedimento como qualquer interação necessária entre os empreendedores (ou seus procuradores) e algum órgão, departamento ou guichê durante a formalização ou em até três meses após o registro, desde que sejam globais, isto é, não aplicável apenas a um segmento específico e que não esteja relacionado a ligação elétrica, água, gás ou saneamento. Já o tempo é mensurado em dias corridos, desconsiderando os períodos para reunir os documentos/informações necessárias pelo empreendedor. Os custos são todas as despesas oficiais, emolumentos, serviços jurídicos ou de outros profissionais exigidos em lei para a constituição da empresa. Para fins de comparabilidade, o custo é o percentual entre esses valores apurados e a renda per capita da economia analisada em dólar. O mesmo padrão percentual é adotado para o capital mínimo integralizado, isto é, algumas economias exigem um depósito inicial de capital social para a constituição de empresas, fato que não ocorre em 111 das 190 (58\%) das economias analisadas, inclusive o Brasil (WORLD BANK, 2016a; 2017).

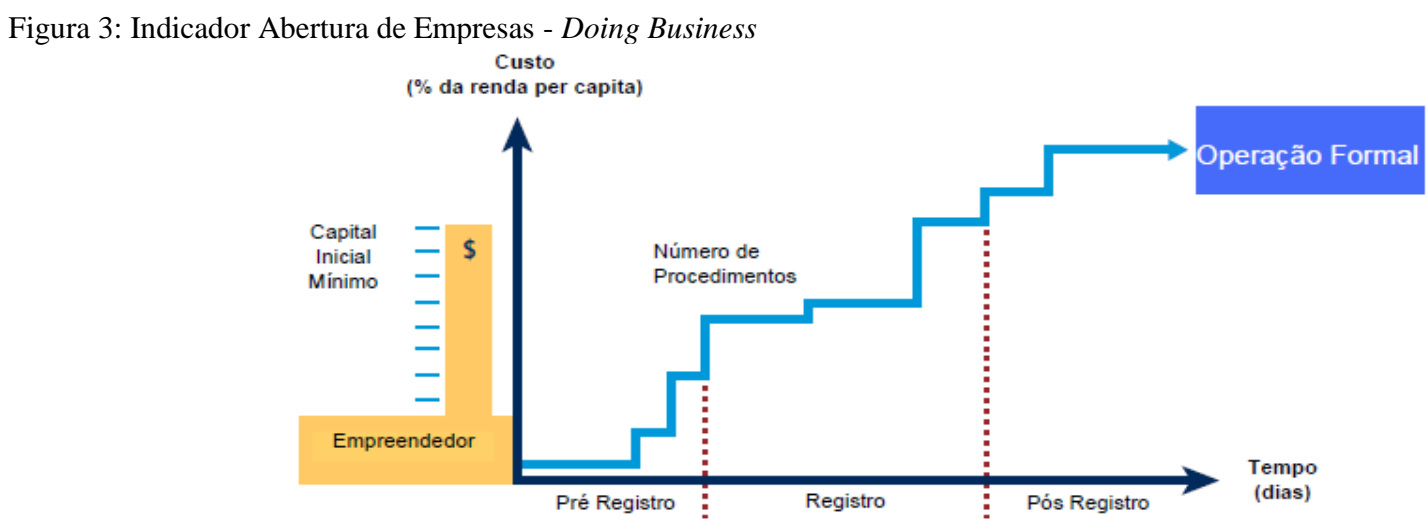

Fonte: World Bank, 2017, p. 117 (tradução nossa)

O Doing Business (WORLD BANK, 2017), isto é, a análise dos indicadores identificados ocorre em dois métodos de avaliação diferentes; a distância para a fronteira e o ranking de facilidade dos negócios. A distância para a fronteira baseia-se na escolha de uma economia com resultado referência e então as demais são avaliadas quanto a suas distâncias frente ao benchmarking, em uma escala de 0 a 100; pior resultado e a economia referência, respectivamente. Esse formato permite que sejam avaliadas as evoluções das economias em 
termos absolutos, pois em contrapartida o ranking deflagra apenas a posição de determinada economia em relação as demais. Por exemplo, pode ter havido evolução, mas que ocorreu em velocidade inferior as concorrentes (demais economias) e, de alguma maneira, isso precisa ser considerado: o porquê aquele país é pior ou melhor de se fazer negócios.

Uma importante restrição de um estudo mundial é a sua aplicação generalista local, uma vez que a análise se baseiam apenas nas principais cidades dos países. No Brasil, é utilizado uma composição ponderada entre os resultados encontrados pelas cidades capitais de São Paulo e Rio de Janeiro, compondo os indicadores por 61 e 39 por cento, respectivamente (WORLD BANK, 2017).

Quanto aos resultados do relatório de 2017 o Brasil encontra-se na posição $123^{\circ}$ portanto, 64\% das economias são mais fáceis para fazer negócio ao Brasil. Quanto à distância para a fronteira (DTF) resulta no valor de 56,53. O melhor resultado é da Nova Zelândia, seguido por Singapura e Dinamarca. Inúmeros países da América do Sul estão à frente do

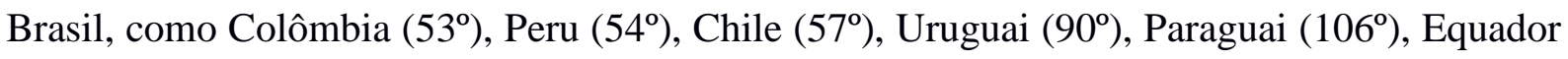
$\left(114^{\circ}\right)$ e Argentina $\left(116^{\circ}\right)$ (WORLD BANK, 2017).

Quando avaliado o indicador Abertura de Empresas a posição do Brasil fica ainda pior; em $175^{\circ}$ lugar; contudo, seu DTF é maior, com 65,04. Isto ocorre porque é uma área os países dedicam muito esforço, tanto que quarenta e nove economias apresentaram melhorias substanciais (acima de $2 \%$ no DTF), sendo consideradas reformas, neste ano da análise. O Brasil foi um deles, sendo identificado as mudanças ocorridas na cidade do Rio de Janeiro com o Rio Mais Fácil, que automatizou com um portal online o processo de licenciamento empresarial, dentro dos conceitos preconizados pela Redesimples (WORLD BANK, 2017).

De maneira geral foram identificados a necessidade de onze diferentes procedimentos nas duas capitais analisadas, com um custo de US\$ 492,50 (4,1\%) em São Paulo e US\$ 669,80 (6,8\% da renda per capita) no Rio de Janeiro; em conversão direta na data de 05 de janeiro de 2017 esses valores são de R \$ 1.574 e R \$ 2.141, respectivamente. Destacam-se ainda os tempos médios necessários de 45 dias no Rio de Janeiro e 101 dias em São Paulo para abrir um negócio no Brasil. Como benchmarking internacionais encontra-se a Nova Zelândia com apenas um processo, em um tempo de meio dia e, portanto, online para abrir uma empresa e a Eslovênia com nenhum custo (WORLD BANK, 2016a; 2017).

Importante destacar a afirmação de Augusto Lopez-Claros, Diretor do Grupo de Indicadores Globais do Banco Mundial, que produz o relatório de que "o Doing Business coleta dados a respeito das regulações de negócios, para incentivar a introdução de regulações eficientes, acessíveis e simples", pois "as decisões dos governos têm um impacto importante 
nas operações diárias das pequenas e médias empresas, e regulações restritivas e onerosas podem consumir a energia dos empreendedores e dificultar a inovação e o desenvolvimento das empresas". Corroborando, Paul Romer, vice-presidente sênior do Banco Mundial que "regras simples e transparentes são um sinal de respeito de um governo por seus cidadãos. Elas têm um impacto direto na economia, ao estimular o empreendedorismo, a igualdade de gênero e o respeito ao Estado de direito" (WORLD BANK, 2016b).

Tão importante a avaliação situacional do Brasil no contexto em análise no mundo que se faz imprescindível o conhecimento do arcabouço legal envolvido, que permeia desde conceitos da Constituição Federal até instruções normativas da área da saúde.

\subsection{ARCABOUÇO LEGAL}

Os pequenos negócios; pessoas jurídicas que faturam até 3,6 milhões de reais por ano; representam 98\% do total de empresas de Santa Catarina e 46\% dos empregos formais, tem assegurado tratamento diferenciado e favorecido desde a elaboração da Carta Magna vigente, através dos artigos 170 e 179 (SEBRAE, 2016c; BRASIL, 2016a). Portanto, ao tratar de legalização empresarial não poderia ser diferente e há a necessidade explícita de processos diferenciados para esta parte da economia.

O Estatuto dos Pequenos Negócios completou dez anos de existência em 2016 e pode ser considerado uma lei viva (SMPE, 2014), justamente pelas suas constantes atualizações que já somam pelo menos seis leis complementares. No escopo desta legislação, há alguns dispositivos que tratam em específico sobre os processos de abertura, alteração e baixa empresarial.

Um impacto colateral, mas bastante expressivo foi a criação do Microempreendedor Individual; MEI; que visa oportunizar um registro e modalidade tributária simplificada, ágil e acessível para atividades de baixa complexidade, tais como cabelereira, pipoqueiro ou encanador. Ainda de acordo com a legislação, existem alguns requisitos importantes de serem cumpridos pelo poder público, já definidos em lei, como a impossibilidade de cobrança de quaisquer custos, além da guia mensal, seja relativo à abertura, inscrição, registro, alvará, licença, alteração, baixa ou outros do MEI (BRASIL, 2016b).

Já de impactos diretos, destacam-se dois dispositivos definidos no capítulo de alteração e baixa do Estatuto das Micro e Pequenas Empresas na qual exige que todos os níveis de governo deverão realizar os processos de maneira a considerar a unicidade, devendo se articularem para integrarem seus procedimentos, evitando as duplicidades e de maneira a 
"garantir a linearidade do processo, da perspectiva do usuário". Adicionalmente que os referidos processos de abertura, alteração e baixa de empresas precisarão ter trâmite especial e simplificado para os pequenos negócios (BRASIL, 2016b, Art. $4^{\circ}$ ).

Contudo o arcabouço legal referente aos processos escopo desta investigação não se limitam apenas a Constituição ou Lei Complementar, sendo descritos em suas continuidades de aplicação por Leis Federais e Estaduais também. Nesse contexto, inclusive, surge o termo Redesim ou Redesimples através da lei 11.598 de 2007. A Rede Nacional para a Simplificação do Registro e da Legalização de Empresas e Negócios traz elementos essenciais para a operacionalização desta agilidade e simplificação pretendida, como o estabelecimento de consulta prévia, que deve ocorrer em até quarenta e oito horas e precisa responder ao empreendedor se a localização e o nome empresarial previstos poderão ocorrer caso haja o processo de formalização. Outro elemento bastante importante para tornar o processo mais ágil está na explicitação que as vistorias poderão ocorrer após o início do funcionamento do empreendimento para os casos de baixo risco e, portanto, torna o empreendedor auto declarante que cumpre os requisitos mínimos sanitários, ambientais e de pânico e incêndio (BRASIL, 2007).

A auto declaração é um elemento central para a agilidade e simplificação do processo, na qual o poder público flexibiliza suas técnicas de controles prévios, que exigem mais servidores e tempo, pois as vistorias não podem ser planejadas, precisando ocorrer dispersas em segmento e localidade, para responsabilizar o empreendedor pelo cumprimento. Nesse mesmo sentido, em Santa Catarina, região foco deste estudo, houve a sanção em 2017 de legislação que corrobora estes procedimentos entre Junta Comercial, Bombeiros, Vigilância Sanitária e Meio Ambiente - FATMA (SANTA CATARINA, 2017).

Por fim, importante discutir ainda nos aspectos teóricos quanto ao conceito de federalização dos entes, que diante do artigo dezoito da Constituição Federal, exarou poderes administrativos, financeiros e políticos para o exercício de governo e administração próprios estados e municípios (BRASIL, 2016a). Portanto, assim traz-se mais um elemento para a discussão de processos transversais quanto à competência; que é o registro, alteração e baixa empresarial; pois haverá inúmeros intervenientes distintos que poderão adotar regras locais, não gerando uma uniformidade.

Destarte, temos uma revisão teórica quanto aos elementos para a discussão da situação dos municípios de Santa Catarina para adoção dos conceitos da Redesimples, desde aspectos globais, passando pela contextualização do ambiente nacional e, por fim, legal. No próximo capítulo, será demonstrado os aspectos metodológicos que foram utilizados para análise dos 
municípios catarinenses quanto aos seus processos de abertura, alteração e baixa empresarial e alinhamento ao arcabouço legal.

\section{ASPECTOS METODOLÓGICOS}

A metodologia de uma pesquisa compreende as classificações da pesquisa, as técnicas utilizadas e seus respectivos instrumentos. Dessa forma, esta seção tem como objetivo apresentar a metodologia utilizada, frisando o tipo de pesquisa, suas principais características e os procedimentos utilizados para coleta e análise dos dados.

Para Marconi e Lakatos (1990, p. 19), “[...] os critérios para a classificação dos tipos de pesquisa variam de acordo com o enfoque dado pelo autor. A divisão obedece a interesses, condições, campos, metodologia, situações, objetivos, objetos de estudo etc". Esta pesquisa pode ser classificada como um estudo descritivo, do tipo estudo de caso, uma vez que pretende descrever os fatos e fenômenos de determinada realidade (TRIVIÑOS, 2006). O autor ainda aborda que um dos tipos de estudos descritivos é denominado estudo de caso e que seu grande valor é "[...] fornecer o conhecimento aprofundado de uma realidade delimitada que os resultados atingidos podem permitir e formular hipóteses para o encaminhamento de outras pesquisas" (TRIVIÑOS, 2006, p. 111).

Classifica-se ainda como pesquisa documental, pois foram buscados, em documentos utilizados como fontes de informações, indicações e esclarecimentos sobre o caso em análise. Como principais fontes consultadas, há a legislação e os portais dos municípios (SÁ-SILVA; ALMEIDA; GUINDANI, 2009). Além disso, a técnica de coleta de dados de observação direta, na qual identifica-se provas observacionais sobre comportamentos ou condições ambientais relevantes foram importantes para a compreensão do funcionamento empírico dos processos, principalmente nos pontos de atendimento ao empreendedor, além de subsidiarem as entrevistas semiestruturadas, que ocorreram com os gestores públicos municipais baseados nos temas prioritários levantados nas técnicas anteriores (NETO; BARBOSA; CENDÓN, 2006).

Segundo Richardson (1999), pode-se ainda diferenciar as pesquisas de uma forma bastante ampla, adotando uma classificação em torno de dois grandes métodos: o quantitativo e o qualitativo.

Para esse autor,

[...] o método quantitativo, como o próprio nome indica, caracteriza-se pelo emprego da quantificação tanto nas modalidades de coleta de informações, quanto no tratamento delas por meio de técnicas estatísticas, desde as mais simples como percentual, média, desvio-padrão, às mais complexas, como coeficiente de [correlação], análise de regressão etc. Já o método qualitativo difere, em princípio, do 
quantitativo à medida que não emprega um instrumental estatístico como base do processo de análise de um problema. Não pretende numerar ou medir unidades ou categorias homogêneas (RICHARDSON, 1999, p. 70).

Sendo assim, a presente pesquisa utiliza-se de ambos os métodos, e as escolhas justificam-se pelo objetivo da investigação, o qual visa se aprofundar na análise dos dados com entendimento do processo atual, quanto em quantificar em um último momento para dimensionamento das ações necessárias para responder ao problema de pesquisa proposto. Para a análise dos dados quantitativos, utilizou-se a estatística de correlação pelo Coeficiente de Person, que é um índice adimensional com valores situados entre - 1,0 e 1.0 inclusive, que reflete a intensidade de uma relação linear entre dois conjuntos de dados (BELFIORE, 2015).

Portanto, esta pesquisa classifica-se como descritiva, do tipo estudo de caso, utilizando a pesquisa documental, observação e entrevista semiestrutura, fazendo análises pelos métodos qualitativo e quantitativo.

Inicialmente houve a sistematização das legislações que tratam do caso, pois há um impacto direto no processo To Be; desenho dos processos de como deverão ser; pois quaisquer nuances legais podem acrescentar os dispensar inúmeros procedimentos burocráticos. Paralelamente foi mapeado a abertura, alteração e baixa empresarial de duas importantes cidades catarinenses que demonstraram interesses de seus gestores públicos em transformar os processos atuais. Em um terceiro momento, utilizando a Rede de Agentes de Desenvolvimento fomentada pelo Sebrae/SC de servidores públicos municipais que recebem capacitação e buscam implantar melhorias no desenvolvimento de suas cidades e dos consultores que os acompanham, foi possível mapear o processo geral estadual, a partir de entrevistas semiestruturadas.

Para compreensão do nível de integração dos sistemas foi realizada observação e entrevista com os servidores do município de Timbó que, por fim, subsidiaram a construção do instrumento de coleta de dados para a entrevista que resultou em dados quantitativos sobre os atuais processos de abertura, alteração e baixa de empresas nos municípios catarinenses. Portanto, o alcance dos resultados foi adquirido após a aplicação de cinco momentos de pesquisa diferentes de interação com o meio, todos no ano de dois mil e dezesseis, que estão esquematizados conforme figura abaixo.

Figura 5: Etapas de interação para alcance dos resultados

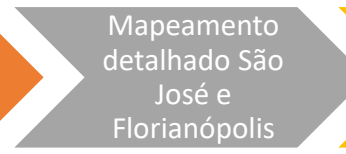

Florianópolis
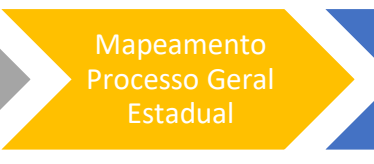

Análise de

Integração

Sistemas Timbó
Entrevista com

33 municípios

Fonte: Elaborado pelos autores 
Todos os trinta e cinco municípios participantes fizeram parte do estudo a partir de um plano amostral por conveniência, nos municípios que o Sebrae/SC atuou no ano de 2016 com a implantação de políticas de desenvolvimento, contando com o importante contato do Agente de Desenvolvimento como articulador em nível municipal. Dessa forma, os municípios que fizeram parte desta pesquisa estão apresentados no quadro a seguir.

Quadro 2: Municípios participantes da pesquisa
\begin{tabular}{|l|l|}
\hline Extremo Oeste & Anchieta, Maravilha e São João do Oeste \\
\hline Foz do Itajaí & Brusque, Camboriú e Itajaí \\
\hline Grande & Florianópolis, São José, Angelina, Rancho Queimado e São \\
Florianópolis & Bonifácio \\
\hline Meio Oeste & Caçador, Fraiburgo, Herval d'Oeste, Ipira, Joaçaba, Luzerna e Peritiba \\
\hline Norte & Araquari, Campo Alegre, Jaraguá do Sul e Papanduva \\
\hline Oeste & Chapecó, Passos Maia e Seara \\
\hline Serra & Abdon Batista, Correia Pinto e Lages \\
\hline Sul & Jacinto Machado, Lauro Muller e Tubarão \\
\hline Vale do Itajaí & Indaial, Pomerode, Timbó e Trombudo Central \\
\hline
\end{tabular}

Fonte: Elaborado pelos autores

Com estas análises, subsidiados por marcos teóricos de desempenho globais e regionais poderão ser definidas etapas necessárias para a implantação integral da Redesimples nos municípios de Santa Catarina.

$\mathrm{Na}$ próxima seção poderão ser conferidos os resultados destes cinco momentos de interação com os trinta e cinco municípios catarinenses visando analisar a situação desses para a implantação dos conceitos de simplificação dos processos de abertura, alteração e baixa empresarial.

\section{RESULTADOS}

Nesta seção apresentam-se os resultados da pesquisa nos municípios catarinenses, após a compreensão do panorama internacional, nacional e legal que os processos de abertura, alteração e baixa de empresas estão envoltos.

\subsection{MAPEAMENTO DE PROCESSOS DE FLORIANÓPOLIS E SÃO JOSÉ}

Durante o ano de 2016 foi desenvolvido pelo Sebrae/SC; Serviço de Apoio às Micro e Pequenas Empresas de Santa Catarina; um projeto de mapeamento das rotinas atuais necessárias para abrir, alterar ou encerrar um empreendimento nos municípios de Florianópolis e São José. A metodologia ocorreu por análise documental de informações disponíveis em meios oficiais dos órgãos, seguido por entrevistas com contadores e funcionários dos órgãos envolvidos, 
gerando como resultado fluxogramas funcionais, para obter uma visualização da cadeia de processos, gráficos de Gantt, para observar as escalas de tempo necessário e tabela "De-Para", para identificar o fluxo dos documentos, separados por portes empresariais. Com todo o processo mapeado identificou-se os pontos críticos que representam procedimentos gargalos nos processos (SEBRAE, 2016a; 2016b).

Como conclusão do mapeamento, encontrou-se fluxos altamente complexos, inclusive com dificuldade de apresentação gráfica em páginas de leitura, requerendo dimensões especiais de papel para impressão. A quantidade de procedimentos são reflexos de inúmeros órgãos envolvidos e que não possuem integração, somado ainda as diferenças em cada município, conforme percebe-se no Quadro 3.

Especificadamente em Florianópolis apresentou-se como pontos críticos as pendências dos empreendedores ocorridas pela falta de documentos exigidos para a tramitação do processo, dificuldade e falha de comunicação destes e a prefeitura. Os licenciamentos constituem os principais responsáveis pelo acréscimo do tempo total e inclusive, estes procedimentos apresentaram precedências sem explicações, ou seja, órgãos esperam respostas de outros para efetuarem suas análises, por mais que estas sejam independentes e sem vinculação. De acordo com a análise da instituição, uma empresa nas mesmas características das analisadas pelo Doing Business ou ICE, demora em média 156 dias para abertura na capital catarinense.

A cidade vizinha, pertencente a conurbação da Grande Florianópolis, apresenta os mesmos pontos críticos da relação empreendedor e prefeitura, integração entre os órgãos e demora sendo ocasionada pelos licenciamentos, além disso, a viabilidade de instalação; etapa prévia a qualquer registro empresarial e definida em lei; não tem os dados nela analisados para as etapas subsequentes. Na cidade de São José a demora em média apurada foi de 113 dias para a abertura de uma empresa.

Quadro 3: Participação de Órgãos nos Processos - Municípios de Florianópolis e São José

\begin{tabular}{|c|c|c|c|c|}
\hline Agente & $\hat{A}$ mbito & Abertura & Alteracão & Baixa \\
\hline Portal do Empreendedor & Federal & $\mathrm{X}$ & $\mathrm{X}$ & $\mathrm{X}$ \\
\hline Receita Federal & Federal & $\mathrm{X}$ & $\mathrm{X}$ & $\mathrm{X}$ \\
\hline Previdência Social & Federal & $\mathrm{X}$ & & $\mathrm{X}$ \\
\hline $\begin{array}{l}\text { JUCESC (Junta Comercial do Estado } \\
\text { de Santa Catarina) }\end{array}$ & Estadual & $\mathrm{X}$ & $X$ & $\mathrm{X}$ \\
\hline $\begin{array}{l}\text { CBMSC (Corpo de Bombeiros } \\
\text { Militar de Santa Catarina) }\end{array}$ & Estadual & $X$ & $\mathrm{X}$ & \\
\hline Polícia Civil & Estadual & $\mathrm{X}$ & $\mathrm{X}$ & \\
\hline $\begin{array}{l}\text { SEFAZ (Secretaria Estadual da } \\
\text { Fazenda) }\end{array}$ & Estadual & $X$ & $X$ & $X$ \\
\hline SMDU & Florianópolis & $\mathrm{X}$ & $\mathrm{X}$ & \\
\hline Secretaria do Continente & Florianópolis & $\mathrm{X}$ & $\mathrm{X}$ & \\
\hline Pró-Cidadão & Florianópolis & $\mathrm{X}$ & $\mathrm{X}$ & $\mathrm{X}$ \\
\hline SMFPO & Florianópolis & $\mathrm{X}$ & $\mathrm{X}$ & $\mathrm{X}$ \\
\hline Secretária Municipal da Saúde & Florianópolis & $\mathrm{X}$ & $\mathrm{X}$ & \\
\hline
\end{tabular}




\begin{tabular}{|c|c|c|c|c|}
\hline FLORAM & Florianópolis & $\mathrm{X}$ & $\mathrm{X}$ & \\
\hline $\begin{array}{c}\text { Secretaria Municipal de Urbanismo e } \\
\text { Serviços Públicos }\end{array}$ & São José & $\mathrm{X}$ & $\mathrm{X}$ & \\
\hline Centro de Atendimento ao Cidadão & São José & $\mathrm{X}$ & $\mathrm{X}$ & $\mathrm{X}$ \\
\hline Secretária Municipal da Saúde & São José & $\mathrm{X}$ & $\mathrm{X}$ & \\
\hline $\begin{array}{c}\text { Fundação Municipal do Meio } \\
\text { Ambiente }\end{array}$ & São José & $\mathrm{X}$ & $\mathrm{X}$ & \\
\hline Secretária Municipal da Receita & São José & $\mathrm{X}$ & $\mathrm{X}$ & $\mathrm{X}$ \\
\hline
\end{tabular}

Fonte: Adaptado de Sebrae, 2016a; $2016 b$.

Quando analisado estes dois municípios, devido a suas importâncias econômicas e interesses públicos na alteração da realidade foi verificado que a análise nesses não poderia ser generalizado, principalmente para o quesito falta de informação e integração, pois devido a peculiaridade de não serem signatárias no sistema informatizado atual, incentivado pela Junta Comercial do estado; REGIN - Registro Mercantil Integrado. Portanto, foi necessário a avaliação dos atuais sistemas envolvidos nos processos em análise e suas integrações.

\subsection{ANÁLISE DOS SISTEMAS ATUAIS E INTEGRAÇÕES}

O conceito de federalização dos entes pode ser muito bem percebido no processo de registro de uma empresa, principalmente por seu ônus de cada ente ter suas decisões independentes e não considerar o ambiente, gerando falta de integração e repetições desnecessárias. Cada estado, o distrito federal e os municípios possuem procedimentos diferentes de execução, mesmo que baseados na mesma legislação de suporte.

Para demonstrar o fluxo atual, será descrito, do ponto de vista do empreendedor o trâmite genérico de Santa Catarina para registro empresarial identificado.

Assim que o empreendedor inicia o processo de formalização o primeiro passo seria a consulta de viabilidade, conforme discutido no item Arcabouço Legal. Em Santa Catarina não existe esse trâmite formal e padrão, passando diretamente para o passo seguinte (BRASIL, 2007).

O empreendedor deve solicitar pedido de viabilidade via REGIN no site da JUCESC, solicitar o DBE/CNPJ no site da Receita Federal, preencher o requerimento eletrônico (RE) no site da JUCESC. De acordo com a FECAM (2017), 98,6\% dos municípios catarinenses possuem o módulo do REGIN. Esse foi implantado pela Junta Comercial em janeiro de 2006 com vistas a integração de órgãos e informatização do processo.

Em seguida, deve submeter fisicamente o Contrato Social para a Junta Comercial, juntando os comprovantes dos passos anteriores para verificação jurídica do ato, autorização e registro pelo órgão estadual responsável. 
Recebendo a autorização da Junta Comercial quanto à conformidade do Contrato Social, o empreendimento tem o CNPJ (Cadastro Nacional de Pessoa Jurídica) liberado, passando para os registros e autorizações estaduais e municipal, como a inscrição nos órgãos governamentais, registro em órgãos de classe e autorização para nota fiscal, por exemplo.

Feito o procedimento anterior, o empresário precisa entrar no sistema municipal e informar os dados para a constituição da empresa; basicamente o nome empresarial, nome fantasia, tipo empresarial, enquadramento de porte, objeto social, dados dos sócios, capital social, e localização. Paralelamente, caso o município tenha o convênio com o REGIN o processo é repassado para que que este avalie o empreendimento quanto as conformidades municipais. Mesmo havendo diferenças sensíveis das exigências em cada município, em suma é avaliada a conformidade junto ao plano diretor; se aquele tipo de empresa pode se instalar naquela localidade; de vigilância sanitária, ambiental, incêndio e pânico e fazenda, existindo cobranças de taxas variadas para cada órgão avaliar e praticamente em todos os casos necessitando de vistoria prévia in loco para a autorização do funcionamento.

O que é verificado são alguns pontos críticos ao longo desta tramitação. Inicialmente a falta de integração entre o preenchimento para a Receita Federal e para os órgãos Estadual e Municipal. Caso haja convênio este último é integrado, do contrário há um terceiro cadastro geral. Além disso, para a análise da Junta Comercial é necessário levar fisicamente cópias dos documentos dos sócios, vias do Contrato Social e comprovante de pagamento da taxa.

Quando da análise pelo município, também é necessário entregar fisicamente os mesmos documentos, novamente, solicitar a taxa e fazer o pagamento. Dessa maneira, haverá a análise pela área de planejamento do município e meio ambiente. Ocorre que é necessária a análise da vigilância sanitária do município e para tal, é necessário deslocar-se até esse órgão, entregar os mesmos documentos, novamente, solicitar a guia da taxa, pagar e entregar o comprovante e, somente assim, teremos essa análise e vistoria para a concessão do alvará sanitário.

O Corpo de Bombeiros Militar é um órgão de competência estadual e já adota os conceitos da Redesimples, refletindo assim, em todos os municípios catarinenses. Portanto, para a análise de incêndio e pânico, a vistoria para funcionamento de empresa em imóvel de baixa complexidade o empreendedor precisa acessar o sistema do Corpo de Bombeiros Militar, realizar o preenchimento dos dados, e será informado (via internet) em relação as medidas de segurança necessárias para a empresa. Após o pagamento da taxas e assinatura no termo de compromisso (via internet) com as medidas de segurança descritas nas orientações, o mesmo receberá automaticamente o atestado de vistoria para funcionamento. A fiscalização poderá ser 
realizada pelo Corpo de Bombeiros Militar a qualquer momento, após a concessão do atestado de funcionamento. No caso de vistoria para funcionamento de empresa em imóvel de alta complexidade, a concessão do atestado de funcionamento dependerá da vistoria prévia.

Feito isso, é necessário reunir todos estes documentos e autorizações, leva-los a prefeitura para que esta dê o aceite final e autorize o funcionamento do empreendimento.

Em termos gerais, todas as empresas precisam passar por todos estes órgãos (Junta Comercial, Receita Federal, Prefeitura Municipal, Vigilância Sanitária, Corpo de Bombeiros), inevitavelmente, e poderão necessitar de outras autorizações também como do órgão estadual de meio ambiente ou Polícia Civil - divisão de jogos e diversões. Além de, exigência de órgãos de representação ou fiscalização, como Conselho de Medicina Veterinária, Engenharia e Arquitetura.

Ainda, as legislações municipais podem exigir a entrega dos mesmos documentos ou de mais alguns específicos para outros órgãos, como meio ambiente, trânsito, obras ou inúmeros outros.

Ainda há recorrência de procedimentos e uma consequente demora quanto aos procedimentos da vigilância sanitária e demais órgãos municipais, pois o sistema autorizador desta parte do fluxo (REGIN) não é integrado ao sistema de gestão do órgão. Necessitando que o servidor público após a sua análise, em sistema e método próprio, dê entrada nas respostas novamente para que o processo possa dar continuidade.

Assim, tem-se precedência de atividades entre órgãos, um sistema informatizado de registro dos trâmites, mas necessitando de entregas físicas dos mesmos ou documentos extras em cada órgão que o analisa. Além disso, quando da resposta negativa ou pendência não é efetuado registro em sistema, necessitando que o empreendedor se comunique com o órgão para dirimir as eventuais pendências encontradas.

Feita a análise global do processo, parte-se para conhecer as peculiaridades de uma amostra de municípios, para assim conseguir definir os procedimentos para a implantação integral da Redesimples nos municípios de Santa Catarina, de maneira uniforme e efetiva.

\subsection{DIAGNÓSTICO NOS MUNICÍPIOS CATARINENSES}

Para o alcance da proposição das ações e do formato de articulação para a implantação da Redesimples em Santa Catarina, após a análise legal e de uma visão bastante detalhada do processo em dois municípios complexos e observação geral do funcionamento dos demais, foi 
necessária a aplicação particular de uma entrevista e observação em uma amostra mais abrangente de municípios para conhecimento das realidades regionais.

Para isso, foram selecionados os temas chaves para conhecimento da realidade individual dos municípios, com base nas etapas anteriores e os resultados encontrados foram bastante uniformes, demonstrando que os aspectos analisados são essenciais para a implantação. Portanto, foi possível materializar as respostas em resultados quantitativos, compilados na figura a seguir.

Figura 6: Compilação Resultados da análise nos municípios

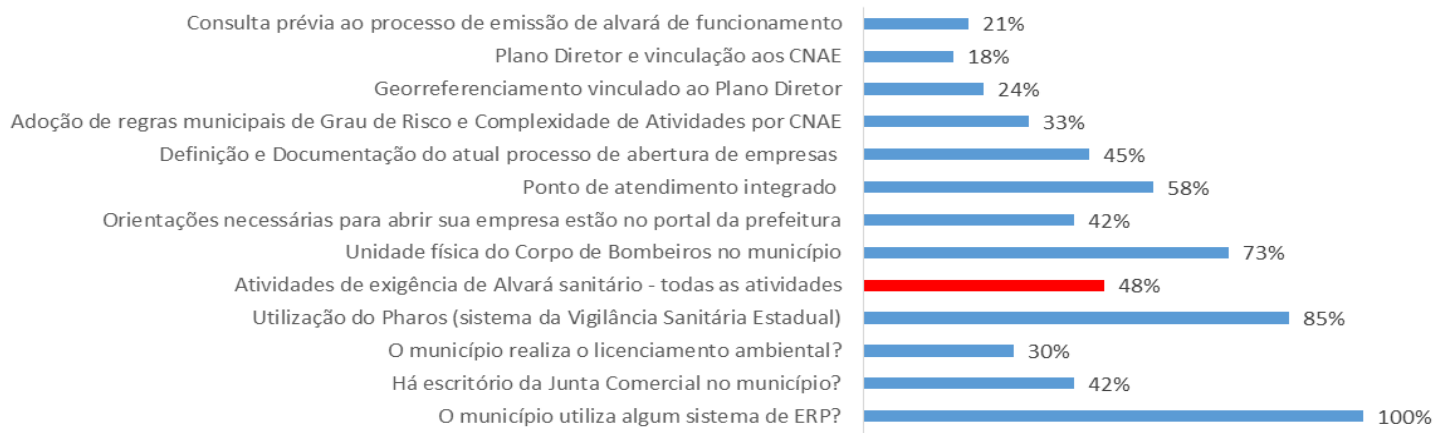

Fonte: Elaborado pelos autores

De acordo com os resultados, pode-se verificar que todos os municípios já possuem um sistema integrado de gestão - ERP - concentrados em duas grandes fábricas de software, o que é um aspecto bastante oportuno quando se planeja uma uniformização e entendimento das dinâmicas municipais dos registros, principalmente contábil e fiscal.

A consulta prévia para emissão do alvará de funcionamento, conforme determina a Lei 11.598/07 é um ponto de atenção, mas já identificada nas etapas de visão global do processo, na qual, nos municípios analisados, apenas $21 \%$ possuem, sendo todos bastante diferentes e sem informatização (BRASIL, 2007). Ainda para a consulta prévia, o plano diretor com vinculação pelo Cadastro Nacional de Atividade Econômica e este georreferenciado são os aspectos de menor presença nos municípios. Há na análise algo importante para ser considerado, todos estes três aspectos estão inter-relacionados e são do sub processo de consulta prévia, portanto encontra-se aqui o principal ponto fraco para a adoção dos critérios da Redesimples e desburocratização dos processos de abertura e alteração empresarial.

Dois terços dos municípios não possuem regras municipais ou adotam o conceito de grau de risco para o licenciamento empresarial. Esse era um fato bastante esperado, pois conforme discutido no referencial teórico o entendimento em nível estadual só ocorreu início deste ano (2017) com a sanção do Bem Mais Simples (SANTA CATARINA, 2017). Do outro lado, há um terço dos municípios que já adotam em algum grau o conceito de risco para seu 
licenciamento; fato plenamente legal, pois há legislação nacional que já deveria ser cumprida pela integralidade dos municípios; que são de uma concentração bastante regional do oeste catarinense com Anchieta, Chapecó, Fraiburgo, Herval D’Oeste, Ipira, Joaçaba, Luzerna e Peritiba. Contudo, há dois municípios no Vale, além de três municípios identificados em cada uma das regionais da Grande Florianópolis, Norte, Serra e Sul.

Menos da metade dos municípios não possuem seus processos de abertura, alteração ou baixa de empresas e, portanto, nem os próprios donos do processo em âmbito local possuem uma visão holística de quão confuso este pode ser. É um fato importante na consideração quanto a políticas de estímulo a desburocratização, uma vez que o mapeamento e entendimento prévio da dinâmica deve ser considerado, inclusive para alinhamento interno da prefeitura. $\mathrm{O}$ desconhecimento é explicitado ainda, na qual há repetição de menos da metade, novamente, de municípios com informações compiladas e dedicadas para explicar ao empreendedor quais os requisitos e documentos necessários para a abertura de empresa. A interação destas variáveis é nítida pelo contexto, mas também em testes estatísticos que chegam ao coeficiente de correlação (Person) em 0,57.

Quanto a infraestrutura disponibilizada pelos licenciadores em âmbito estadual, é verificado uma importante disseminação nos municípios, com $73 \%$ dos pesquisados com unidade licenciadora do Corpo de Bombeiros Militar e $85 \%$ do sistema informatizado de controle das atividades (Pharos) disponibilizado pela Diretoria de Vigilância Sanitária. No gráfico de compilação dos resultados, houve grifo da análise da variável de exigência de alvará sanitário pois a sua polaridade de análise é invertida; quanto menos, melhor. Além disso, o resultado encontrado de $48 \%$ das prefeituras exigindo para todas as atividades alvará sanitário vem a corroborar a justificativa da discussão do tema de desburocratização dos processo de legalização empresarial, pois este é o órgão que na análise do mapeamento detalhado em Florianópolis e São José mais adicionaram tempo ao processo e pela descaracterização de seu papel. De acordo com o IBGE (2007) há 1.318 CNAEs, contudo é evidente que algumas destas atividades são dispensáveis de alvará sanitário, pois não representam escopo para avaliação de tal licenciador. Ocorre que há taxas para emissão destes alvarás e, portanto, é criado obrigatoriedade para todos por fins arrecadatórios. Exemplos de não competência são fabricação de equipamentos, construtoras, usinas, representante comercial, vendedores (que não sejam de alimentos), instalação e reparação hidráulica, dentre muitas outras.

A informação quanto ao licenciamento ambiental é de extrema relevância, pois desde 2011 os municípios têm autonomia para iniciarem esta fiscalização, dispensando a intervenção de órgãos estaduais, conforme a Lei Complementar 140 (BRASIL, 2011). De acordo com o 
Conselho Estadual do Meio Ambiente de Santa Catarina, há 85 municípios no estado que optaram pela habilitação e realização, no mínimo, em partes do licenciamento em âmbito local (CONSEMA/SC, 2016). Estes valores não são considerados nesta pesquisa, pois nem facilitam ou dificultam os processos de legalização empresarial, apenas são variáveis importantes de serem conhecidas.

O escritório da Junta Comercial no município permite que o empreendedor ou seu procurador não precisem deslocar-se até um município vizinho para protocolarem e entregarem os documentos físicos requeridos, como Contrato Social, cópia dos documentos dos sócios, comprovantes de pagamento e realização dos procedimentos anteriores. Menos da metade dos municípios (42\%) afirmaram ter um escritório local. Contudo, o esperado pelo marco legal é justamente não necessitar dos escritórios locais pela entrega, análise e resultado dos procedimentos inteiramente digitais (BRASIL, 2007).

E, por meio desta análise detalhada encerra-se o diagnóstico nos municípios catarinenses que envolveu duzentas e quarenta horas na análise dos processos detalhados em Florianópolis e São José, investigação por quatro meses do cenário estadual, visita técnica em Timbó para conhecimento da integração dos sistemas e outros trinta e dois municípios com aplicação de entrevistas semiestruturadas e observação por um mês dentro das unidades de análise apresentada.

\section{CONSIDERAÇÕES FINAIS}

Desta maneira, a proposta de analisar a situação atual dos municípios para a implantação da Redesimples em Santa Catarina foi discutida partindo de uma análise macro, quanto a discussão de modelos teóricos de gestão pública, na qual percebeu-se a situação atual descrita na literatura como Administração Burocrática e que o estudo propõe uma visão de New Public Management, contudo não alcança as premissas descritas como Novo Serviço Público. Em seguida pode-se discutir quanto aos conceitos de crescimento e desenvolvimento econômico e seu inter-relacionamento com o movimento empresarial e pesquisa mundial que relaciona diretamente o desenvolvimento econômico de uma nação e suas políticas de facilidade de geração de negócios.

Quanto ao processo de abertura, alteração e baixa empresarial, foi avaliado o ambiente internacional e nacional deste tema, através de pesquisas de instituições como Banco Mundial e Endeavor. Por fim, o referencial contou com uma visão geral, integrada e sequenciada entre 
os principais normativos brasileiros e do estado de Santa Catarina quanto aos processos em análise.

Na pesquisa, foram dedicadas análise da capital, Florianópolis e cidade conturbada, São José, passando por desdobramento de análise global dos demais municípios da unidade federativa, as integrações entre os Sistemas de Gestão Municipal - ERP e o processos de abertura, alteração e baixa de empresas, até o diagnóstico em trinta e três municípios, representando todas as regiões e diversidades político-econômicas. O diagnóstico permitiu um agrupamento dos resultados encontrados em unidades de análise quanto aos procedimentos municipais que interagem com a legalização empresarial.

Assim, verificou-se uma situação uniforme em todo o estado de Santa Catarina e preocupante, pois a legislação nacional traz o prazo de cinco dias para a abertura de uma empresa (e quarenta e oito horas para a consulta de viabilidade), na qual os resultados encontrados foram inexistência do procedimento de viabilidade e valores muito superiores quanto ao prazo (BRASIL, 2007).

Por fim, foi possível alcançar o objetivo proposto de analisar a situação dos municípios catarinenses para a implantação da Redesimples, recomendando-se como pesquisas futuras a avaliação da recém regulamentação estadual e a dinâmica de divulgação e buscas pela simplificação dos municípios catarinenses. 


\section{REFERÊNCIAS}

BARROS, Aluízio Antonio; PEREIRA, Cláudia Maria Miranda de Araújo.

Empreendedorismo e Crescimento Econômico: uma Análise Empírica. RAC, Curitiba, v.12, n.4, p. 975-993, out/dez 2008.

BELFIORE, Patrícia. Estatística Aplicada: Para Cursos de Administração, Contabilidade e Economia com Excel e SPSS. 1 ed. São Paulo: Elsevier, 2015.

BORGES, Jussara Maria. A gestão universitária de projetos de extensão na perspectiva da gestão social: um estudo de caso no Centro Socioeconômico - CSE/UFSC, no período de 2009 a 2012. 2013. 288 p. Dissertação (Mestrado em Administração Universitária).

Departamento de Ciências da Administração, Centro Socioeconômico, Universidade Federal Federal de Santa Catarina. 2013.

BRASIL. Constituição da República Federativa do Brasil: texto consolidado até a Emenda Constitucional n. 95, de 15 de dezembro de 2016a.

Lei 11.598. Estabelece diretrizes e procedimentos para a simplificação e integração do processo de registro e legalização de empresários e de pessoas jurídicas, cria a Rede Nacional para a Simplificação do Registro e da Legalização de Empresas e Negócios REDESIM, de 3 de dezembro de 2007.

$2016 b$.

Lei Complementar $\mathbf{n}^{\mathbf{0}}$ 123: texto consolidado até a LC 155, de 27 de outubro de

Lei Complementar $\mathbf{n}^{\circ}$ 140, de 8 de dezembro de 2011.

BRESSER-PEREIRA, Luiz Carlos. Crescimento e Desenvolvimento Econômico. Notas para uso em curso de desenvolvimento econômico na Escola de Economia de São Paulo da Fundação Getúlio Vargas. Versão de junho de 2008. Disponível em:

http://www.bresserpereira.org.br/papers/2008/08.18.ConceitoHist\%C3\%B3ricoDesenvolvime nto.31.5.pdf. Acesso em: 01/02/2017.

CONSEMA/SC. Municípios Habilitados para o Exercício do Licenciamento de Atividades com Impacto Ambiental Local. Florianópolis, 2016. Disponível em: http://www.sds.sc.gov.br/index.php/biblioteca/consema/municipios-habilitados/348municipios-habilitados/file. Acesso em: 01/02/2017.

DEMETRIO, Diego Wander. GARRIDO, Paulo Otolini. A Metodologia de Planejamento Estratégico Municipal do Sebrae/SC: uma avaliação segundo os modelos de Administração Pública. In: NETO, Luis Moretto; et al [org.]. Contribuição para a gestão pública municipal. vol. 2, Florianópolis: Departamento de Ciências da Administração / UFSC; [Brasília]: CAPES: UAB, 2014.

DJANKOV, Simeon; et al. The Regulation of Entry. Quarterly Journal of Economics, Cambridge (USA), v. CXVII, n. 1, p. 1-37, fev 2002.

ENDEAVOR. Índice de Cidades Empreendedoras Brasil 2016. 2016. Disponível em: http://endeavor.org.br/indice-cidades-empreendedoras-2016/. Acesso em: 03/01/2017. 
FECAM. Página eletrônica do Consórcio de Informática na Gestão Pública Municipal CIGA fundado e gerido pela FECAM - Federação Catarinense de Municípios. Apresenta dados de seus consorciados. Disponível em: http://ciga.sc.gov.br/consorciados/. Acesso em: $10 / 01 / 2017$.

FROES, César; MELO NETO, Francisco Paulo. Administração pública. Rio de Janeiro: UCB/EB, 2006.

GOMES, Maria Lucineide Serpa; OLIVEIRA, Francisco Correia de. Modelos organizacionais de administração pública: um estudo dos aspectos da realidade cearense na estrutura de referência das reformas do Estado. Revista de Ciências da Administração, Florianópolis, v. 12, n. 28, p. 105-126, set.-dez.2010.

IBGE. Classificação nacional de atividades econômicas - CNAE : versão 2.0. [Acompanha CD-Rom]. Rio de Janeiro: IBGE, 2007.

MARCONI, Marina de Andrade; LAKATOS, Eva Maria. Técnicas de pesquisa: planejamento e execução de pesquisas, amostragem e técnicas de pesquisa, elaboração, análise e interpretação de dados. 2. ed. São Paulo: Atlas, 1990.

MOREIRA, Sandrina Berthault; CRESPO, Nuno. Economia do Desenvolvimento: das abordagens tradicionais aos novos conceitos de desenvolvimento. Revista de Economia, Curitiba, v. 38, n. 2, p. 25-50, maio/ago 2012.

NETO, Rivávia C. Drummond de Alvarenga; BARBOSA, Ricardo Rodrigues; CENDÓN, Beatriz Valadares. A construção de metodologia de pesquisa qualitativa com vistas à apreensão da realidade organizacional brasileira: estudos de casos múltiplos para proposição de modelagem conceitual integrativa. Revista Informação \& Sociedade, João Pessoa, v. 16, n. 2, p. 69-86, jul/dez 2006.

OLIVEIRA, Gustavo Justino. Modelos teóricos da administração pública. In: IESDE. Administração pública. Campinas, 2010. p. 1-10.

PESSALI, Huáscar; DALTO, Fabiano. A mesoeconomia do desenvolvimento econômico: o papel das instituições. Nova Economia, Belo Horizonte, v. 20, n. 1, p. 11-37, jan-abril 2010.

RAMOS, Alberto Guerreiro. A nova ciência das organizações: uma reconceituação da riqueza das nações. 2. ed. Rio de Janeiro: FGV, 1989.

RICHARDSON, Roberto Jarry. Pesquisa social: métodos e técnicas. São Paulo: Atlas, 1999.

SANTA CATARINA. Lei 17.071. Dispõe sobre as regras comuns ao Enquadramento Empresarial e das Entidades de Fins não Econômicos Simplificado (EES) e à Autodeclaração e estabelece outras providências, de 12 de janeiro de 2017.

SÁ-SILVA, Jackson Ronie; ALMEIDA, Cristovão Domingos; GUINDANI, Joel Felipe. Pesquisa documental: pistas teóricas e metodológicas. Revista Brasileira de História e Ciências Sociais, São Leopoldo, v. 1, n. 1, p. 1-15, jul. 2009.

SEBRAE. Relatório de consultoria: Levantamento dos Registros, Alteração e Baixa de Empresas em Florianópolis, 2016a. 
Relatório de consultoria: Levantamento dos Registros, Alteração e Baixa de Empresas em São José, 2016b.

Relatório interno: Cenário Externo de Atuação: coletânea de informações socioeconômicas - Santa Catarina, Brasil, 2016c.

SECCHI, Leonardo. Modelos organizacionais e reformas da administração pública. Revista de Administração Pública, Rio de Janeiro, v. 43, n. 2, p.347-369, mar./abr. 2009.

STEL, André van; CARREE, Martin; THURIK, Roy. The Effect of Entrepreneurial Activity on National Economic Growth. Small Business Economics, New York (USA), v. 24, n. 3, p. 311-321, abril 2005.

TRIVIÑOS, Augusto N. S. Introdução à pesquisa em ciências sociais: a pesquisa qualitativa em educação. 1. ed. 14. reimp. São Paulo: Atlas, 2006.

WEBER, Max. Economia e sociedade: fundamentos da sociologia compreensiva. Brasília: Editora Universidade de Brasília, 1991.

WORLD BANK. Comunicado à imprensa. Record Number of Economies Carried Out Business Reforms in Past Year: Doing Business. Disponível em:

http://www.worldbank.org/en/news/press-release/2016/10/25/record-number-of-economiescarried-out-business-reforms-in-past-yeardoing-business. Washington, DC. 25/10/2016b. 2017.

Doing Business 2017: Equal Opportunity for All. Washington, DC: World Bank,

. Página eletrônica dedicada a informações, bancos de dados e notas para a imprensa referente a metodologia do Doing Business, em português. Disponível em: http://portugues.doingbusiness.org/. Acesso em: 29/12/2016, 2016a. 